\title{
A Constituição de um Pensamento Latino-Americano Sobre Assuntos Internacionais ${ }^{1}$
}

\section{Eduardo Devés-Valdés}

Profesor e investigador del Instituto de Estudos Avanzados de la Universidad de Santiago de Chile, Idea-Usach. $<$ www.eduardodevesvaldes.cl>. eduardo.deves@usach.cl

\section{INTRODUÇÃO}

Como pensar uma política exterior, e os temas internacionais em geral, a partir de critérios elaborados no âmbito do pensamento da América Latina e do Caribe (ALC)? Melhor: Como aproveitar tudo que se teorizou na ALC para pensar os assuntos internacionais, sem COM isso cair em nenhum tipo de chauvinismo ou autoctonismo que fechasse todo o aproveitável procedente de outros lugares? Como aproveitar ou capitalizar toda nossa produção de ideias sobre questões internacionais? Como organizar ou reconhecer essa produção e torná-la utilizável, pô-la à disposição daqueles que fazem teoria e daqueles que são agentes internacionais no sentido mais amplo?

\footnotetext{
${ }^{1}$ Intervenção realizada no âmbito da Terceira Jornada sobre "Política Exterior da Bolívia" organizada pela OEA e pela Udabol, em La Paz e Santa Cruz de la Sierra.

Tradução do professor doutor André Leonardo Copetti Santos (Programas de Pós-Graduação em Direito da Unijuí e da URI).
} 
No limite dessas perguntas, trata-se de avançar até a elaboração de teorias que sejam, de certo modo, adaptadas aos requerimentos de uma comunidade que busca inserir-se no meio ambiente global: ocupar nichos e ampliá-los. Trata-se, de outra parte, de assumir uma reflexão sobre questões internacionais emergida nas regiões periféricas e mostrar, particularmente aos que estudam Relações Internacionais, e que muitas vezes imaginam que não há temas para investigação, a imensa quantidade de espaços inexplorados que existem.

\section{BICENTENÁRIO, POBRE DESEMPENHO DE NOSSOS PAÍSES E POLÍTICA EXTERIOR}

2010 foi um ano emblemático para muitos de nossos países. A comemoração do bicentenário da independência no Chile e na Argentina constitui-se em um motivo para realizar avaliações do que fizemos e projeções acerca do que desejamos. O ano de 2010 não encontra a ALC em uma situação invejável, e por certo não me refiro à crise econômica mundial que hoje em dia se faz sentir, mas a questões de um tempo mais distante.

Ante tal situação de debilidade, não devemos avançar explicações simplistas ou monocausais. Melhor, devemos supor que todos os âmbitos de nossa tarefa foram deficitários e particularmente aqueles que são chaves impulsionadoras de círculos virtuosos. Quase unicamente posso enfrentar o tema do bicentenário desde minha especialidade, os Estudos Eidéticos, é dizer, os estudos sobre as ideias ou sobre o pensamento. Necessito, entretanto, fazer algumas reflexões sobre a realidade, para avançar logo sobre os aspectos teóricos.

Refiro-me particularmente a assuntos como: as baixas posições no ranking de desenvolvimento, elaborado pelo Pnud; os escassos aportes em ciência e em tecnologia que fazemos para nosso próprio bem-estar 
e para o mundo; as baixíssimas posições de nossos países quando se comparam com os padrões educacionais obtidos por outros; o avanço de certas enfermidades ou pragas e o aumento da pobreza, em muitos casos; a pobre incidência de nossos Estados no espaço mundial e a desídia para apresentar nossa cultura e nossas opções ao mundo por meio de formas de comunicação eficientes.

Não pretendo estar capacitado para fazer um balanço da situação, da inserção, da condição internacional da ALC até o bicentenário. Apenas atrevo-me a assinalar alguns pontos. Penso que o melhor, compreendendo todos os aspectos, que pode exibir a ALC, nos últimos cem anos, é a existência de guerras internacionais e capitalizar o respeito internacional por haver sido capaz de coexistir por quase um século e meio sem guerras importantes, sendo a Guerra do Chaco a única e a exceção que confirma a regra. A paz internacional é o maior êxito da ALC em seus dois séculos de vida independente. Diferente é sua inserção internacional, classificada entre medíocre e baixa.

Sem dúvida, porém, fomos melhores em relação ao que não nos ocorreu (as guerras internacionais) pelo que fomos capazes de construir além de nossas fronteiras. Muitos de nossos objetivos no âmbito mundial não se cumpriram, sendo o da integração latino-americana um dos mais frustrados. De fato, a inexistência de uma política internacional compartilhada de longo prazo é também exemplo dessa deficiência.

Obviamente, entende-se que temos diferenças entre Bolívia e Chile, entre Venezuela e Colômbia, entre Argentina e Uruguai ou entre Nicarágua e Costa Rica, para citar alguns casos, mas isso não deve impedir que sejamos capazes de gerar algumas políticas de fôlego sobre questões que são comuns, tais como: uma diplomacia cultural e científico-tecnológica compartilhada, uma política internacional de imagem, uma colaboração diplomática em países distantes nos quais temos pobre ou nula representação, como ocorre em numerosíssimos países da Ásia e da África. De fato, 
tampouco temos uma política exterior compartilhada para os milhões de pessoas procedentes da ALC que vivem fora de nossos territórios: nos EUA, Canadá, Espanha, Austrália e tantos outros países.

Instituímos ao acaso uma paupérrima, para não dizer miserável, política científico-tecnológica ao exterior como países e pior, como região: somos incapazes de captar a ciência e a tecnologia, de atrair, de gerir internacionalmente a questão de patentes, royalties, etc.; de exportar nosso conhecimento e vendê-lo, e sobretudo de comparar e atrair a comunidade científica até nossas universidades e instituições de ensino e investigação. Ademais, nossa política internacional normalmente foi incapaz de pensar uma unidade maior que o Estado-nação.

Por outra parte, e indo às causas de alguns problemas: é certo que temos figuras capazes de pensar a questão internacional, mas carecemos de uma assessoria regional sobre estes assuntos. Existem organismos internacionais como a OEA, o Instituto para a Integração da América Latina e do Caribe (INTAL), o Banco Interamericano de Desenvolvimento (BID) ou a Secretaria Geral da Comunidade Ibero-Americana de Nações (SEGIB), que de algum modo podem contribuir para esta tarefa, como também alguns centros de caráter nacional, mas até o momento fomos incapazes de gerar e gerir uma assessoria permanente sobre questões internacionais, tal como tivemos a Comissão Econômica para a América Latina (CEPAL), como um think thank sobre questões econômicas que, emitindo uma voz, se constitua em uma referência da reflexão.

Agora, retornando ao tema específico, creio que não se está gerando um pensamento que sirva de insumo, por assim dizer, aos inumeráveis agentes não estatais (empresas, igrejas, universidades, ONGs, organismos culturais, desportivos e outros) que desde a ALC pretendem inserir-se de alguma maneira em espaços metanacionais e o que possuímos não estamos capitalizando nesse sentido. Em 2006, na Universidade de Torcuato Di Tella, Robert Russel afirmou que "El estado de avance y producción 
del pensamiento teórico sobre temas internacionales en la Argentina hoy es pobrísimo, es realmente pobrísimo, casi no hay, y lo que hay es totalmente subsidiario de lo que producen las grandes potencias y es realmente pobre" (Russel, 2006). Se é verdade o que assinala Russel para a Argentina, e, sem dúvida, ele conhece mais disso que eu, como será o grau de pobreza do que produz a Bolívia, o Chile e tantos outros países da região que, neste plano, têm notoriamente menor desenvolvimento que a Argentina? De outra parte, entretanto, Raúl Bernal-Meza mostrou-nos que, ainda que pouco, não deixam de existir numerosos avanços neste sentido (BernalMeza, 2005).

\section{CAPITALIZAÇÃO DO PATRIMÔNIO EIDÉTICO QUE POSSUÍMOS}

O pensamento da ALC foi-se ampliando por todas as partes do mundo nas últimas décadas. $\mathrm{O}$ volume de produção intelectual cresce cada vez mais rápido e isso é algo quase óbvio. Menos óbvio é que vão se abrindo mais e mais espaços de reflexão e vão se desenhando novos temas e novos problemas.

Historicamente o pensamento latino-americano aproximou-se de numerosos assuntos, mas no imaginário da intelectualidade não especialista permaneceu algo arraigado ao problema do "pensamento nacional", que foi um dos seus temas clássicos. Mais recentemente os assuntos econômicos, particularmente desenvolvimento/dependência, e na dimensão política a questão democracia/ditadura estiveram em discussão. Nenhuma destas interrogantes e reflexões se esgotou, mas a própria dinâmica de uma comunidade intelectual estimulada, algo angustiada, algo frustrada por breves êxitos e mais longos fracassos, foi se obrigando a formular-se novos assuntos. 
Faz já duas décadas que o tema da globalização vem sendo o mais recorrente, sendo, por outra parte, um tema mundial e que por todas as partes se coloca em disjuntiva como a questão da(s) identidade(s). Coloca-se tanto no centro como nas periferias. Nas regiões periféricas coloca-se profusamente. $\mathrm{O}$ assunto da globalização, porém, ainda que tratado sempre em relação à identidade, por sua vez está cruzado por outra situação: a ameaça e a oportunidade. Direi que a maioria do pensamento das regiões periféricas o assume como ameaça ou franco perigo, ainda que retoricamente sempre se observa que se trata por sua vez de uma possibilidade ou de uma oportunidade.

Não é ali, porém, onde quero chegar se não ao fato de que na ALC está se desenvolvendo cada vez com mais abundância, com maior nível técnico e mais tematicamente um pensamento sobre questões internacionais, sobre a inserção da ALC no mundo, sobre o processo de mundialização, sobre as relações entre a região e outras do mundo.

De fato, em todas essas discussões subjazem considerações que têm a ver como assuntos internacionais, de modo mais ou menos direto. Curiosamente, entretanto, as próprias pessoas que trabalharam sobre estes assuntos nem sempre estiveram conscientes do que tais colocações envolvem, não sendo capazes de considerar e de capitalizar tudo o que possuem. E quero dizer de passagem que não há suficiente preocupação sobre isto. Prova disso é que nas múltiplas cátedras, carreiras, Pós-Graduações, academias diplomáticas, organismos regionais, não temos consciência de nossa produção, não temos cursos em que isto se ensine e nem sequer os manuais necessários para tanto. Penso que isto não pode ser assim, que não estamos sequer capitalizando o pouco que produzimos.

Fazer um exercício de exploração de nossos territórios intelectuais para cartografá-los desde o ponto de vista da produção existente sobre questões internacionais parece uma tarefa necessária. Nossos territórios eidéticos foram recorridos em numerosas ocasiões, mas houve poucas 
pessoas que se interessaram sobre esta dimensão, deixando-a frequentemente de lado. De fato, existe na ALC e em geral nas regiões periféricas uma pequena mas relativamente importante produção eidética que, em todo caso, estamos desperdiçando.

\section{ALGO QUE JÁ TEMOS: patrimônio eidético latino-americano}

O que pretendo é apresentar-lhes uma cartografia que de uma maneira simples e didática desenhe algumas das ideias que se manejaram sobre assuntos internacionais (e tenhamos em conta que tampouco fizemos um dicionário da produção eidética da ALC sobre assuntos internacionais).

\subsection{Cartografia do patrimônio eidético sobre assuntos internacionais}

\subsubsection{Primeiro: Os conceitos e categorias}

\subsubsection{Categorias compreensivas:}

- Centro/Periferia - Raúl Prebisch

- Nacionalismo/Colonialidade - Carlos Montenegro

- Realismo Periférico - Carlos Escudé

- Grandes Estados Periféricos - Samuel Pinheiro Guimarães

- Identidade Internacional - Celso Lafer

\subsubsection{Dimensão Econômica:}

- Deterioração nos termos do intercâmbio - Raúl Prebisch

- Desenvolvimento para o exterior/para o interior: Raúl Prebisch 
- Distribuição heterogênea da ciência e da tecnologia: Raúl Prebisch;

- Dependência estrutural: F. H. Cardoso

4.1.1.3 O assunto da integração:

- Integracionismo, integração latino-americana - inúmero(a)s autore(a)s

- União americana - Sociedade União Americana, Francisco de P. Vigil

- Nacionalismo continental - Felipe Herrera

- Integracionismo Aberto - Cepal anos 1990

4.1.1.4 Conceitos associados (aqueles que não se referem especificamente ao internacional, mas que se utilizaram para):

- Luso-tropicalismo: Gilberto Freyre

\subsubsection{Segundo: As ideias}

4.1.2.1 Ideias sobre a integração, união, etc.:

- Integracionismo político - Manuel Ugarte

- Integracionismo econômico - Víctor R. Haya de la Torre

- Integracionismo cultural, indústrias culturais e idiomas ibéricos - José E. Rodó, Néstor García Canclini

- Integracionismo social - Marcus Garvey, Lincoln Bizzozzero

- Integracionismo sub-regional (amazônico, platino, andino, conosulenho, caribenho e centro-americano) - União Democrática Centro-americana, Vicente Sáez, Mario Sancho, Norman Girban, Andrés Serbin;

4.1.2.2 Ideais sobre economia internacional:

- Sobre a União Aduaneira - Alejandro Bunge 
- Sobre o comércio justo, as matérias-primas e o estabelecimento de tratados mais equitativos: Raúl Prebisch, Unctad;

- Sobre a ação das empresas multinacionais: Osvaldo Sunkel, Ilet

4.1.2.3 Ideias sobre anti-imperialismo:

- Recuperação do território do Canal do Panamá - Víctor R. Haya de la Torre

- Revolução terceiro-mundista mundial: Ernesto Guevara, Fidel Castro

- A compensação pela recuperação das riquezas básicas deve fazer-se calculando os investimentos como também as grandes utilidades que obtiveram: Doutrina Allende (Salvador Allende)

\subsubsection{Ideais sobre a paz:}

- O rechaço do emprego da força por parte de uma nação sobre outra para cobrar uma dívida: Doutrina Calvo (Carlos Calvo) e Drago (Luís María Drago)

- Sobre o não reconhecimento de territórios obtidos pela força: Doutrina Saavedra Lamas

- Contra a corrida armamentista e não proliferação de armas nucleares: Alfonso García Robles

- Sobre os direitos humanos no espaço internacional - Oscar Arias

4.1.2.5 Ideias sobre a inserção no espaço global:

- Sobre o comércio justo e o diálogo norte/sul - Raúl Prebisch

- Desde a doutrina da segurança nacional - Golbery do Couto e Silva, Edgardo Mercado Jarrín

- A partir da solidariedade com os países do Terceiro Mundo - Fidel Castro, Ernesto Guevara, Salvador Allende 
- Gestão de organizações da sociedade civil no espaço internacional Lincoln Bizzozzero

4.1.2.6 Ideias sobre a autodeterminação dos povos:

- Sobre prescindir do reconhecimento das mudanças de governo em outros Estados, assumindo o direito de permanecer ou retirar as representações diplomáticas - Doutrina Estrada (Genaro Estrada)

4.1.2.7 Ideias sobre a teoria dos estudos internacionais e teoria da história dos assuntos internacionais:

- Sobre os paradigmas - Amado Cervo, Raúl Bernal-Meza, Joaquín Fermandois

\section{O TEMA DA INTEGRAÇÃO COMO EXEMPLO DE REELABORAÇÃO EIDÉTICA}

Apresentaram-se duas cartografias que permitem orientar-se, ainda que seja primariamente, no que pode denominar-se como a produção latino-americana em estudos internacionais. Estas cartografias, porém, da mesma forma que nos estudos geográficos, não são simplesmente "retratos" ingênuos ou cabais da realidade, senão que se fez articular ênfase no tema da integração e se mostraram algumas conexões com outros conceitos e ideias.

Proponho-me na continuação, e como último ponto, a trabalhar a título de exemplo, com um dos conceitos mais recorrentes (e por isso mesmo mais manuseados e desvirtuados) do pensamento latino-americano sobre questões internacionais, precisamente o da "integração". Este conceito encontra-se na base de projetos como da Associação Latino-Americana de Livre Comércio (Alalc), o Mercado Comum do Sul (Mercosul), a Comunidade Andina de Nações (CAN) ou a Unasul, tanto como de organismos como o BID (Banco Interamericano de Desenvolvimento, o Insti- 
tuto para a Integração Latino-Americana (Intal) e o Convênio Andrés Bello $(\mathrm{CAB})$, e dentro do $\mathrm{CAB}$ o Instituto Internacional de Integração. É dizer, um conceito que ainda que tenha servido para uma imensa quantidade de palavrório oco, também inspirou ou fundamentou numerosas iniciativas, com melhor ou pior sorte.

É possível imaginar uma série de cenários de elaboração teórica a respeito da integração, realizando combinações em uma espécie de jogo de engenharia ou de culinária que permita confeccionar, a partir de componentes básicos e do ingrediente fundamental que é a noção "integração”, produtos eidéticos mais elaborados. Ao menos em uma primeira etapa é requisito deste jogo empregar unicamente elementos procedentes da produção latino-americana. Devo insistir que estou falando desde os estudos eidéticos e não como internacionalista nem tampouco como um expert em política exterior. A ideia é trabalhar desde os estudos eidéticos para potencializar interdisciplinarmente os estudos internacionais. Deste modo, o assinalado está particularmente destinado às e aos estudantes que se ocupam destas disciplinas e que devem realizar investigações que renovem, melhorem ou cultivem o patrimônio existente.

Vários dos conceitos e ideias que foram apresentados nas cartografias estão muito pouco teorizados ou pouco constituídos teoricamente para alcançar uma condição suficiente, de modo que possam ser considerados verdadeiros referenciais nas discussões. "Constituir-los teoricamente" é contribuir para fazê-los mais manuseáveis. Agora, isto de reconceitualizar e dar-lhes maior consistência teórica para fazê-los mais aptos pode entender-se em dois sentidos: como acréscimo do acervo eidético existente ou como afinamento de certas dimensões do já existente, tornando-as mais adequadas.

Para esta tarefa de outorgar maior consistência teórica e fazê-las mais aptas, pode-se proceder com dois métodos: o de reforçar as ideias existentes e o de cruzá-las com outras: “Reforçar” significa acrescentar e/ 
ou fortalecer um conceito ou uma ideia. No meio ambiente das Ciências Sociais a noção de "integração" se usa como "integração social” oposta à marginalidade e como integração "internacional” oposta à "desagregação", a "separatismo" em ocasiões, a "nacionalismo" ou "soberania nacional” dentre outras. Neste caso, quando se fala de "integração” assume-se como "integração latino-americana" e, como se pode perceber, teve boa quantidade de protoconcepções e logo derivações ou ramificações. Neste plano, a noção integração foi quase sinônimo de "união americana” (ou "latino-americana”, tendo como seu último período clássico o dos anos 60 , com um conjunto de iniciativas, derivadas em sua maior parte das formulações cepalinas, baseadas em uma interpretação muito elaborada do funcionamento da economia mundial. Segundo Antonio Ocampo, para Raúl Prebisch, "A propagação universal do progresso técnico desde os países originários ao resto do mundo foi relativamente lenta e irregular”. Esta afirmação, com a qual se inicia a que é talvez a mais conhecida, constitui o ponto de partida do pensamento de Prebisch. Este tem uma implicação metodológica fundamental: a dinâmica dos países em vias de desenvolvimento não pode ser analisada independentemente de sua posição dentro da economia mundial. As assimetrias internacionais características do sistema "centro-periferia”, a necessidade de adotar estratégias ativas de “desenvolvimento desde dentro", incluídas aquelas dirigidas a enfrentar os problemas especiais que geram a "heterogeneidade cultural", e o papel crítico (chave) da integração regional, constituem três eixos centrais no pensamento de Prebisch” (Ocampo, 2001). Neste sentido, reforçar reelaborando a noção de “integração" supõe fundamentalmente situá-la em uma nova teoria da economia internacional em tempos de globalização.

Por outra parte, "cruzar" ou combinar o conceito "integração” com outros conceitos, como democracia e sociedade civil, por exemplo, é uma segunda opção para outorgar-lhe consistência. O conceito "integração" manejou-se de maneira um tanto quanto espontânea, como a tendência a constituir (reconstituir) uma grande nação desfeita, ou invertebrada na 
fórmula que Filipe Herrera tomou de José Ortega y Gasset. A noção de “integração” pode cruzar-se com a noção de "sociedade civil”. Esta última teve um desenvolvimento profuso no meio ambiente intelectual latinoamericano até o ano 2000, pouco antes ou pouco depois, particularmente ano âmbito nacional, ainda que aludindo em ocasiões igualmente ao metanacional.

Unir a noção "integração latino-americana” com a noção de "sociedade civil" (Cohen; Arato, 2000) significa, por uma parte, imaginar uma integração realizada desde muitos distintos agentes e significa imaginar uma sociedade civil que não se restringe nem se esgota no interior do Estado-nação. Pelo contrário, concebe uma sociedade civil que transcende o Estado-nação e que se comunica por viagens ou meios eletrônicos, que assume expressão midiática, que se conecta mediante uma institucionalidade com presença metanacional e transfronteiriça.

Essa emergência de uma sociedade civil faz-se particularmente patente para o meio intelectual, na constituição de redes intelectuais metanacionais que assumem papeis acima das soberanias nacionais e que se colocam tarefas de trabalho conjunto, articulando e potencializando instâncias originadas no interior dos Estados-nação. Esta tarefa que é muito antiga na intelectualidade latino-americana, que em medida importante atuou integrada em numerosas iniciativas, sendo talvez a mais importante a constituição de um espaço intelectual comum, com uma trajetória, uma delimitação de campo, uma conceitualização, alguns temas, etc., que permitem falar de um espaço comum latino-americano, em muitos aspectos.

Seria possível pensar que a constituição de redes e de uma sociedade civil intelectual latino-americana é um mero epifenômeno com pouca ou nenhuma relevância, entretanto na hora de assumir a importância da sociedade do conhecimento e da informação, devemos igualmente assumir 
a importante projeção que estas redes podem ter para o futuro da região, por sua própria produção e pelo efeito de demonstração para outros agentes sociais.

O modo de pensar e de atuar da intelectualidade (em certo plano) é um modelo de integração por parte da sociedade civil. A existência, por exemplo, da Universidade Andina Simón Bolívar e do Convênio Andrés Bello, como instâncias culturais e intelectuais intergovernamentais, mas também feitos como a multiplicação das sociedades científicas, dos agrupamentos acadêmicos e das redes intelectuais que se assumem como latinoamericanos e não como nacionais, oferecem um modelo de ação que pode servir para outros agentes sociais, que se situam acima das possibilidades e vontades políticas (ou não) dos Estados e dos governos. Agentes econômicos, agentes sindicais, ONGs, organizações sociais várias, podem tomar exemplos (e vice-versa, por certo) das iniciativas que desde o século 19 vêm desenvolvendo uma intelectualidade que foi criando (ainda que seja com pouca consciência e pouca vontade) uma cultura da interconexão transfronteiriça, das redes e de uma conceitualização que lhe permite pensar-se como totalidade além do Estado-nação. Neste sentido, concebe-se a integração não somente como ocupação dos Estados nem muito menos unicamente dos governos.

Na tarefa de engenharia eidética que se propôs, pode-se ainda lançar mão de outros elementos. Uma possibilidade para avançar nisso consiste em agregar as ideias pan-africanistas emergidas no meio ambiente intelectual do Caribe, durante a primeira metade do século 20. O pan-africanismo é uma aposta a integrar não somente aos Estados africanos e as pessoas que ali vivem, mas a todos os afrodescendentes do mundo em uma tarefa comum de defesa ou promoção do que chamou a raça negra (Devés-Valdés, 2008). 
Realizando um cruzamento entre as ideias integracionistas clássicas e as pan-africanistas podemos pensar o processo de integração não somente como uma questão de Estados, mas também de sociedade civil, mas não tendo apenas em conta a sociedade civil existente em nossos territórios, mas a composta por toda a gente que se considera a si mesma latino-americana, tendo em conta então as nossas numerosas e massivas “colônias” residentes nas diferentes cidades dos EUA, Canadá, Espanha, Europa em geral e Austrália. ${ }^{2}$

\section{CONCLUSÕES E PROJEÇÕES}

Voltemos atrás:

a) começou-se formulando o problema em relação à necessidade de assumir a própria trajetória do pensamento latino-americano para aportar à interpretação e à ação no âmbito internacional;

b) pôs-se em seguida ênfase na conjuntura do bicentenário e na necessidade de realizar uma avaliação dos 200 anos de vida independente, e particularmente da política ou agenda internacional, que permita projetar-nos até o futuro;

c) continuou-se com um conjunto de referências aos âmbitos em que a trajetória do pensamento latino-americano foi constituindo um amplo conjunto de conceitos, trabalhos, critérios, doutrinas e estudos que conformam um patrimônio-capital eidético subutilizado para estudar nossa projeção no mundo;

${ }^{2}$ Nisto é muito importante tomar consciência do que ocorreu, por exemplo, com as numerosas colônias chinesas do Índico e do Pacífico e sua importância comercial, política e na circulação das ideias e das pessoas, ao longo da história moderna da China. 
d) focalizou-se a atenção no tema da integração como um dos mais abordados em nosso pensamento, realizando com ele um exemplo de reelaborações e cruzamentos teóricos que apontem a contemplar a crescente presença da sociedade civil e da intelectualidade no âmbito das exigências da sociedade do conhecimento.

Como conclusão desejo referir-me a quatro pontos:

1) Fazer presente no mundo o patrimônio eidético da ALC

Isto de fazer presente no mundo o patrimônio eidético da $A L C$ que pode soar como enigmático ou obscuro para algumas pessoas, é algo de fundamental importância para melhorar nossa posição no supermercado cultural global. A presença de nossas expressões culturais, não só como formas artísticas, passa pela apresentação ou exibição de critérios, princípios, doutrinas, etc., que provenham da ALC. Nossa presença no espaço global passa não só por jogar bem no campo tal como outros a marcaram, mas também pela participação na marcação mesma do campo e na regulamentação do jogo. Para fazer isto, segundo princípios que nos sejam mais favoráveis, devemos começar nós mesmos a manejar os critérios próprios, mas também sermos capazes de apresentá-los nos foros mundiais e ganhar sua legitimidade.

2) A tarefa do bem-pensar como chave para melhorar a sorte de nossos povos

Se é necessário melhorar a presença e a ação exterior de nossos povos e em geral seu desempenho na sociedade do conhecimento e no espaço globalizado, faz-se necessário criar uma instância de assessoria que facilite aos agentes latino-americanos (estatais ou não) melhores possibilidades de desenvolvimento e inserção no espaço mundial. Faz-se necessário pôr em marcha a criação de um programa de Estudos Internacionais Aplicados que se ocupe de fazer investigações e de entregar assessoria aos milhares e milhares de agentes originários da ALC que aspiram a sobre- 
viver e apostar no macroecossistema global, como: Estados, repartições públicas, governos estaduais e municipais, universidades, organizações de trabalhadores, empresas, ONGs, partidos e agrupamentos políticos, igrejas, corporações desportivas de variadas índoles, entre muitos outros agentes.

Nossa universidade de Santiago do Chile decidiu assumir uma pequena parte deste desafio e já pôs em marcha a primeira etapa de um programa que aponta nesta direção. Apresentou ao Grupo de Universidades de Montevideo, que agrupa um conjunto importante de universidades do Mercosul, uma iniciativa para que este agrupamento sustente tal projeto, mas ainda que a proposta não fosse acolhida, conta-se já com fundos e uma equipe humana para iniciar o trabalho. É a oportunidade para convidar para este foro aqueles que queiram participar desta iniciativa, que tende a ser verdadeiramente regional e não nacional, a propor suas contribuições e pontos de vista, e isso particularmente aos jovens que desejem fazer estudos de Pós-Graduação conosco.

Isto se está pensando como uma ação mais no interior de uma geopolítica do conhecimento e das redes intelectuais da região, uma instância mais que contribua para o desenvolvimento da ALC no âmbito mundial e isso é parte da construção de uma Internacional do Conhecimento, cujo trabalho seja animar e coordenar aqueles que em um amplo sentido exercem a profissão do conhecimento.

3) A inovação teórica

Seria muito ambicioso, improcedente e muito superior as minhas forças, nesta oportunidade, formular uma teoria alternativa às que se manejam quando se analisam os fenômenos internacionais, mas pode-se sim assinalar que a maioria das teorias existentes considera a realidade chamada "internacional” sobre a base da interação de entes que são os "Estados-nação", o que é quase tautológico, pois por isso se diz "internacional”. 
Quando se trata de estudar a existência e o desenvolvimento no mundo de milhões (literalmente, milhões) de agentes, cujas dimensões são tão diferentes como as que separam uma baleia azul de um estafilococo, é melhor imaginar isso que se denomina "espaço internacional" como um âmbito que funciona de maneira similar a um grande ecossistema, em que se atua, se sofre, se morre ou se prospera. Para este efeito, ao menos, não é correto chamar a este ecossistema mundial um “cenário” porque é ridículo imaginar um cenário com milhões de protagonistas, nem "atores" que ali pululam e pugnam por encontrar um lugar sob o sol, pois muitas vezes carecem completamente de "papéis" e apenas se inserem em nichos mínimos desenvolvendo-se como podem. Estas expressões antigas, tingidas de um certo halo aristocrático, podem ser válidas para entender o que ocorria na pequena e provinciana Europa do século 19. Para entender este outro mundo que temos hoje, tão amplo e tão estranho, com seus múltiplos submundos, valem mais novas concepções que aludam a dimensões populares. Em todo caso, mais que a teoria "realista", "idealista" ou "grociana", imaginadas para entender o funcionamento dos grandes agentes estatais, poderia ocupar-se a teoria dos jogos ou das decisões para imaginar e ilustrar os milhões de pequenas estratégias e opções de todos os diversos agentes que se debatem cotidianamente em dito sistema global.

Acredito que, neste sentido, a comunidade dos que estudam os assuntos internacionais não foi capaz de tematizar suficientemente este outro mundo, menos elegante e grandiloquente, mas necessitado de uma teorização que lhe facilite autoentender-se em seus trabalhos "metafronteiriços" ou "metanacionais”, mas qualificá-los de "internacionais” pode ser em muitos casos demasiadamente desproporcional. Inclusive penso que, para este efeito, não é adequado sequer falar de um espaço "internacional”, porque não estamos nos referindo a um espaço determinado somente pelos Estados-nação, senão que é melhor falar de um espaço planetário ou planético, de imensa desordem, no qual formigam e jogam milhões de agentes. 
Insisto nisso: pensar na política exterior como a materialização no espaço internacional no qual se confrontam os interesses de monolíticos Estados-nação, não está errado, mas é tremendamente parcial. Uma visão mais democrática pensará na inserção no mundo da multiplicidade de agentes que assim o desejam. Este agentes, que são nossos cidadãos e cidadãs, necessitam de assessoria para se inserir melhor no meio ambiente mundial. Inclusive podem imaginar-se incubadoras de inserção de agentes que trabalhem em colaboração com nossos Estados ou com nossas associações interestatais. Esta tarefa necessita de teorias e penso que não as temos. Nossas universidades, centros de investigação e think-thanks devem ocupar-se disto.

4) Integração e política exterior do mínimo comum

Ainda que sustentando a concepção de um espaço "planético" que deve ser pensado de maneira distinta do "internacional”, não quero dizer que esta última noção deva descartar-se, senão somente pôr-se em seus justos termos. De fato, podemos imaginar uma certa política exterior comum por parte da região, em que os agentes estatais são decisivos, ainda que nada monolíticos nem possuidores de uma vontade única.

O mundo quanto mais distante está nos vê aos latino-americanos de modo mais homogêneo. De longe não se veem nossas diferenças, senão nossas similitudes. A necessidade de trabalhar sobre a base de uma agenda exterior comum, de "mínimo comum", especialmente no âmbito cultural e científico-tecnológico, no qual praticamente não temos oposições entre nós, aparece como algo do máximo interesse. Chamo político do "mínimo comum” aquele que permite atuar coordenadamente em todos aqueles aspectos sobre os quais somos compatíveis, em que não representamos ameaças para o outro, pondo para este efeito, entre parênteses, aqueles sobre os quais não somos. 
A identidade internacional da ALC, se a temos, é débil e muito pouco relevante no âmbito mundial. Muito mais reconhecida é nossa identidade cultural que, vista de longe, parece mais homogênea, forte, interessante e provedora do que nós mesmos a consideramos. Nossa política exterior de mínimo comum deve afirmar-se de maneira principal em nossa identidade cultural, nossa dimensão mais prestigiosa, sem dúvida, no espaço global, articulando-a ao patrimônio ecológico que deve ser nosso segundo elemento de imagem. ${ }^{3}$.

Entre os dez "Interesses da Política Exterior do Chile" encontram-se: contribuir para o fortalecimento da integração regional; fortalecer a imagem no exterior; contribuir para a inserção do Chile nas redes de ciência e tecnologia mundiais; difundir e promover a cultura chilena no exterior. Parece-me que estes objetivos se revestem de baixíssimos níveis de ameaça para os demais países da ALC e possibilitam justamente acordos de mínimo comum.

Não só isso, porém. São objetivos em que a política exterior pode pensar-se como a política exterior dos Estados, mas também pode pensar-se como a projeção até o mundo dos múltiplos agentes que compõem a nação e melhor ainda como a projeção da nação "nossamericana”. Entendo que isso pode soar a simples romantismo e inclusive populismo ou voluntarismo intelectual. Volto, porém, a insistir: não sou um especialista em relações internacionais e muito menos um agente da política exterior chilena. Somente, desde minha atividade, os estudos eidéticos, quis formular duas ou três propostas e um modelo para pensar melhor a tarefa (ou inserção) de nossos povos no mundo.

Muito obrigado.

${ }^{3}$ Por certo, esta projeção de imagem não carece de riscos, particularmente a segunda dimensão, a ecológica, que nos associa com nossa histórica imagem de produtores de matérias primas, alimentos e minérios, e incapazes de entregar valor agregado aos bens, mas convenhamos que isto, no começo do século 21 não tem o mesmo sentido negativo que teria tido no meio da era industrial. 


\section{REFERÊNCIAS}

BERNAL-MEZA, Raúl. América Latina en el mundo. El pensamiento latinoamericano y la teoría de las relaciones internacionales. Buenos Aires: Nuevohacer, Grupo editorial latinoamericano, 2005.

COHEN, Jean; ARATO, Andrew. Sociedad civil y teoría política. México: FCE, 2000 .

DEVÉS-VALDÉS, Eduardo. O pensamento africano sul-saariano. Conexões e paralelos com o pensamento latino-americano e asiático. Um esquema. Rio de Janeiro: Clacso-Educam, 2008.

DEVÉS-VALDÉS, Eduardo. El pensamiento latinoamericano en el siglo XX. Entre la modernización y la identidad. Tomo I Del Ariel de Rodó a la Cepal; Tomo II Desde la Cepal al neoliberalismo; Tomo III Las figuras de fin de siglo, Biblos-Dibam; Buenos Aires; Santiago, 2000, 2003, 2004.

ESCUDÉ, Carlos. El realismo periférico. Buenos Aires: Planeta, 1992.

GUIMARÃES, Samuel Pinheiro Quinhentos anos de periferia: uma contribuição ao estudo da política internacional. Porto Alegre; Rio de Janeiro: Ed Universidade UFRGS; Contraponto, 2000.

HERRERA, Felipe. Nacionalismo latinoamericano. Santiago: Universitaria, 1967.

LAFER, Celso. La identidad internacional del Brasil. México; Buenos Aires: FCE, 2002.

MONTENEGRO, Carlos. Nacionalismo y coloniaje. La Paz: Juventud, 1943.

OCAMPO, Antonio. Raúl Prebisch y la agenda del desarrollo en los albores del siglo XXI. Revista Cepal № 75, 2001, p. 25-40. Disponível em: <www.revistainterforum.com/pdf/Conferenciade\%200campo.pdf $>$.

RUSSEL, Roberto. 2006. Disponível em: <http://fvaccarezza.wordpress. com/2006/12/01/el-desarrollo-de-la-teoria-de-las-rrii-en-la-argentina-es-pobrisimo>.

www.internacionaldelconocimiento.org

Recebido em 18/7/2013

Aceito em 18/7/2013

Autor convidado. 